\title{
Effect of fluconazole dose on the extent of fluconazole-triazolam interaction
}

\author{
ANU VARHE, KLAUS T. OLKKOLA \& PERTTI J. NEUVONEN \\ Department of Clinical Pharmacology, University of Helsinki and University Central Hospital, Helsinki, Finland
}

1 Azole antimycotics interact with the short acting hypnotic triazolam. The effect of fluconazole dose on the extent of fluconazole-triazolam interaction was investigated in a double-blind, randomized cross-over study of four phases.

2 Eight healthy volunteers received either $50 \mathrm{mg}, 100 \mathrm{mg}$ or $200 \mathrm{mg}$ (400 mg on day 1) of fluconazole or placebo orally once a day for 4 days. On day 4, they took a $0.25 \mathrm{mg}$ oral dose of triazolam, after which plasma samples were collected and pharmacodynamic effects measured for $18 \mathrm{~h}$.

3 The mean area under the triazolam concentration-time curve (AUC) was increased 1.6-, 2.1- and 4.4-fold $(P<0.001)$ by fluconazole $50 \mathrm{mg}, 100 \mathrm{mg}$ and $200 \mathrm{mg}$, respectively. The increase in the elimination half-life of triazolam $\left(t_{\frac{1}{2}, \mathrm{z}}\right)$ varied from 1.3 -fold (fluconazole $50 \mathrm{mg}, P<0.05$ ) to 2.3 -fold (fluconazole $200 \mathrm{mg}, P<0.001)$. The peak concentration of triazolam was also increased significantly during all fluconazole phases; more than twofold by fluconazole $200 \mathrm{mg}(P<0.001)$.

4 The pharmacodynamic effects of triazolam were increased significantly $(P<0.05)$ by fluconazole $100 \mathrm{mg}$ and $200 \mathrm{mg}$.

5 Even a small $50 \mathrm{mg}$ daily dose of fluconazole can interact with triazolam and the extent of the interaction increases with increasing fluconazole dose. When triazolam is used concomitantly with fluconazole $50-200 \mathrm{mg}$, the dose of triazolam should be reduced, accordingly. Simultaneous use of triazolam with higher fluconazole doses should be avoided.

Keywords triazolam fluconazole interaction dose dependent

\section{Introduction}

The short acting benzodiazepine triazolam is metabolized during its first-pass and elimination phases by CYP3A4 [1]. Azole antimycotics are inhibitors of CYP3A4 and can markedly increase the hypnotic effect of triazolam. Fluconazole affects the metabolism of triazolam less than either ketoconazole or itraconazole $[2,3]$.

The present study aimed to investigate the effect of different doses of fluconazole on the pharmacokinetics and pharmacodynamics of triazolam.

\section{Methods}

Subjects and study design

The study protocol was approved by the Ethics Committee of the Department of Clinical Pharmacology, University of Helsinki, and Finnish National Agency for Medicines. Eight healthy volunteers (five females and three males; age range 20-32 years; weight range $53-83 \mathrm{~kg}$ ) signed written informed consent to participate in the investigation. None of the subjects was receiving continuous medication. Volunteers who had received medication within 3 weeks before the commencement of the study were excluded.

A randomized, double-blind, cross-over study design of four phases was used. The phases were separated by

Correspondence: Dr Anu Varhe, Department of Clinical Pharmacology, University of Helsinki, Paasikivenkatu 4, FIN-00250 Helsinki, Finland 
an interval of at least 2 weeks. The subjects were given orally a 4-day-premedication with either fluconazole $50 \mathrm{mg}$, fluconazole $100 \mathrm{mg}$, fluconazole $400 \mathrm{mg}$ on the first day and $200 \mathrm{mg}$ on the next 3 days (referred as fluconazole $200 \mathrm{mg}$ in the text) (Diflucan, Pfizer, Amboise, France) or placebo once a day at $13.00 \mathrm{~h}$. On day 4 , a $0.25 \mathrm{mg}$ tablet of triazolam (Halcion, Upjohn, Kalamazoo, Michigan, USA) was ingested with $150 \mathrm{ml}$ water at $14.00 \mathrm{~h}$ i.e., $1 \mathrm{~h}$ after the last dose of fluconazole or placebo. The volunteers fasted for $3 \mathrm{~h}$ before administration of triazolam and had a light standard meal $4 \mathrm{~h}$ afterwards. Alcohol, coffee, tea or cola and tobacco were forbidden during the test period.

\section{Blood sampling and determination of plasma triazolam and fluconazole}

On day 4, a forearm vein was cannulated with a plastic cannula and blood samples $(10 \mathrm{ml})$ were collected into EDTA-tubes immediately before the administration of triazolam and $0.5,1,1.5,2,3,4,5,6,7$ and $18 \mathrm{~h}$ after it. Plasma was separated within $30 \mathrm{~min}$ and stored at $-40^{\circ} \mathrm{C}$ until assay of triazolam and fluconazole. Plasma triazolam concentrations were determined by gas chromatography with use of a modified method of de Kroon et al. [4] and Gaillard et al. [5]. A Hewlett-Packard (Hewlett-Packard Company, Little Falls, Del.) fused silica capillary column (50\% phenyl), with a length of $30 \mathrm{~m}$ and an internal diameter of $0.53 \mathrm{~mm}$, was used. Column temperature was raised up to $285^{\circ} \mathrm{C}$. Methoxydiazepam was used as an internal standard and an electron-capture detector for detection. The sensitivity of the method was $0.1 \mathrm{ng} \mathrm{ml}^{-1}$ and the coefficient of day-to-day variation was $6.1 \%$ at $0.28 \mathrm{ng} \mathrm{ml}^{-1}(n=15)$ and $3.6 \%$ at $1.88 \mathrm{ng} \mathrm{ml}^{-1}(n=16)$. Fluconazole concentrations were also determined by gas chromatography, using nitrogen-phosphorus-detector [6]. The sensitivity of the fluconazole method was $100 \mathrm{ng} \mathrm{ml}^{-1}$ and the coefficient of day-to-day variation was $2.1 \%$ at $5.3 \mu \mathrm{g} \mathrm{ml}^{-1}(n=12)$.

\section{Pharmacokinetics}

Peak concentrations $\left(C_{\max }\right)$ and concentration peak times $\left(t_{\max }\right)$ were registered directly from the original data. The elimination rate constant $\left(\lambda_{z}\right)$ was determined for each subject from the log-linear part of the individual plasma triazolam curve by regression analysis. The elimination half-life $\left(t_{\frac{1}{2}, \mathrm{z}}\right)$ was calculated from $t_{\frac{1}{2}, \mathrm{z}}=$ $\ln 2 / \lambda_{\mathrm{z}}$. Area under the triazolam plasma concentrationtime curves were calculated by use of the trapezoidal rule $[\mathrm{AUC}(0,18 \mathrm{~h})]$ and with extrapolation to infinity (AUC) by dividing the $18 \mathrm{~h}$ concentration by $\lambda_{\mathrm{z}}$. The $\operatorname{AUC}(0,18 \mathrm{~h})$ of fluconazole on the day 4 refers to the time between 0 and $18 \mathrm{~h}$ after the ingestion of triazolam, i.e., between 1 and $19 \mathrm{~h}$ after the last dose of fluconazole.

\section{Pharmacodynamic measurements}

The pharmacodynamic effects of triazolam were measured immediately after each blood sample by four tests: subjective drowsiness using a $100 \mathrm{~mm}$ long visual analogue scale (VAS), the digit symbol substitution test
(DSST), measuring the number of digits correctly substituted in $3 \mathrm{~min}$, the Maddox wing test measuring the coordination of extraocular muscles and the critical flicker fusion test (CFF) measuring discrimination of the fusion of flickering red light, as described earlier [3]. The subjects were properly trained to do the tests before the trial. For each pharmacodynamic variable, the areas under the response-time curves were determined by the trapezoidal rule for 0 to $7 \mathrm{~h}[\operatorname{AUC}(0,7 \mathrm{~h})]$. The maximum effects were also recorded.

\section{Statistical analysis}

The results are expressed as mean values with s.e. mean and $95 \%$ confidence intervals also given $\left(C_{\max }\right.$, AUC values and $\left.t_{\frac{1}{2}, \mathrm{z}}\right)$, or as median and range $\left(t_{\max }\right)$. The pharmacokinetic and pharmacodynamic data during the placebo and fluconazole phases were compared using the analysis of variance and a posteriori testing with the Tukey's test. If necessary to ensure the validity of the modelling assumptions, the data were transformed before the analysis. The $t_{\max }$ values were compared with non-parametric Friedman's two-way ANOVA and the Wilcoxon signed-rank test. Pearson's product-moment correlation coefficient was used in correlation studies. The statistical program Systat for Windows, version 5.0 (Systat, Evanston, Illinois) was used for the analysis. The chosen significance level was $P<0.05$.

\section{Results}

\section{Pharmacokinetics}

Plasma concentrations of triazolam and fluconazole during various phases are shown in Figure 1. The $C_{\max }$ of triazolam was raised in seven of the eight subjects by fluconazole $50 \mathrm{mg}(P<0.05)$ and fluconazole $100 \mathrm{mg}$ $(P<0.05)$ and in every subject by fluconazole $200 \mathrm{mg}$ $(P<0.001)$, when compared with the placebo phase. Fluconazole $200 \mathrm{mg}$ increased the mean $C_{\max }$ more than twofold.

The mean AUC of triazolam was increased 1.6-fold $(P<0.01)$ by fluconazole $50 \mathrm{mg}, 2.1$-fold $(P<0.001)$ by fluconazole $100 \mathrm{mg}$ and 4.4 -fold $(P<0.001)$ by fluconazole $200 \mathrm{mg}$ when compared with the placebo phase. The individual increases in the AUC of triazolam ranged from 1.3 -fold to 4.3 -fold by fluconazole $100 \mathrm{mg}$ and from 2.5 -fold to 16.0 -fold by fluconazole $200 \mathrm{mg}$.

The $t_{\frac{1}{2}, z}$ of triazolam was increased in seven of the eight subjects by fluconazole $50 \mathrm{mg}$, but in every subject by fluconazole $100 \mathrm{mg}$ and $200 \mathrm{mg}$. The individual increase in the $t_{\frac{1}{2}, \mathrm{z}}$ of triazolam caused by fluconazole $100 \mathrm{mg}$ ranged from 1.4 -fold to 2.8 -fold and by fluconazole $200 \mathrm{mg}$ from 2.0-fold to 3.5-fold (Figure 2). The mean $t_{\frac{1}{2}, \mathrm{z}}$ of triazolam was prolonged from a control value of $3.1 \pm 0.4 \mathrm{~h} 1.3$-fold (to $4.0 \pm 0.3 \mathrm{~h}, P<0.05$ ), 1.8-fold (to $5.5 \pm 0.7 \mathrm{~h}, P<0.001$ ), and 2.3-fold (to $7.0 \pm 0.4 \mathrm{~h}, P<0.001$ ) by fluconazole $50 \mathrm{mg}, 100 \mathrm{mg}$ and $200 \mathrm{mg}$, respectively (Table I). 

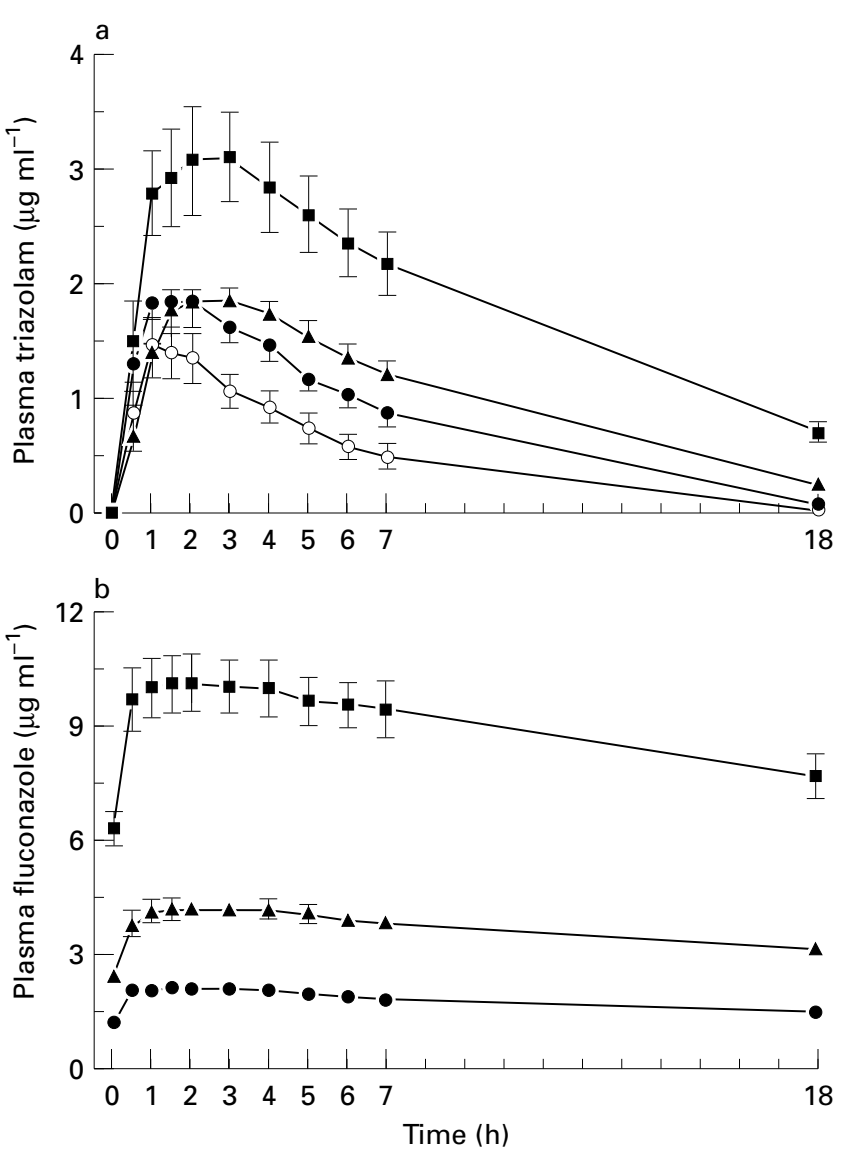

Figure 1 a) The mean plasma concentrations $( \pm$ s.e. mean $)$ of triazolam after an oral dose of $0.25 \mathrm{mg}$ triazolam following pretreatment with fluconazole $50 \mathrm{mg}(\bullet)$, fluconazole $100 \mathrm{mg}$ $(\boldsymbol{\Delta})$, fluconazole $200 \mathrm{mg}(\boldsymbol{\square})$ or placebo $(\bigcirc)$ once daily for 4 days in eight healthy volunteers. b) Plasma concentrations of fluconazole on day 4 . The time zero refers to the administration of triazolam (i.e., $1 \mathrm{~h}$ after administration of fluconazole).

The plasma concentrations of fluconazole on the day of administration of triazolam are shown in Figure 1. The highest plasma concentrations of fluconazole on day 4 , after administration of triazolam, were $2.2 \pm$ $0.1 \mathrm{mg} 1^{-1}$ for fluconazole $50 \mathrm{mg}, 4.4 \pm 0.3 \mathrm{mg}^{-1}$ for fluconazole $100 \mathrm{mg}$ and $10.6 \pm 0.4 \mathrm{mg}^{-1}$ for fluconazole $200 \mathrm{mg}$. The highest fluconazole concentrations, the concentrations of fluconazole at the time of administration of triazolam, and the AUC of fluconazole correlated significantly $(P<0.001)$ with the changes of AUC values of triazolam caused by fluconazole.

\section{Pharmacodynamics}

The pharmacodynamic effects of triazolam during the different fluconazole phases and during the placebo phase are shown in Figure 3. The maximum effects and the $\operatorname{AUC}(0,7 \mathrm{~h})$ of the $\mathrm{CFF}$, subjective drowsiness (VAS), the Maddox wing test and the DSST during the fluconazole $200 \mathrm{mg}$ phase differed significantly $(P<0.05)$ from the placebo phase. Fluconazole $100 \mathrm{mg}$ increased significantly $(P<0.05)$ the maximum effects and the $\operatorname{AUC}(0,7 \mathrm{~h})$ of DSST and CFF. Fluconazole $50 \mathrm{mg}$ did not change significantly any of the tests.

\section{Discussion}

The present results indicate that the extent of the fluconazole-triazolam interaction is clearly dependent on the dose of fluconazole. The $50 \mathrm{mg}$ daily dose of fluconazole caused significant changes in the pharmacokinetics of triazolam, without any effect on the pharmacodynamics. On the other hand, higher doses of 100 and $200 \mathrm{mg}$ resulted in more pronounced pharmacokinetic changes and also increased the effects of triazolam in a dose dependent manner. There were large interindividual differences in the extent of the interaction at each fluconazole dose level, but the correlation between, for example, the increase of the triazolam AUC and the AUC of fluconazole was good. In our earlier study fluconazole $100 \mathrm{mg}$ changed the pharmacokinetics of triazolam to the same extent as fluconazole $100 \mathrm{mg}$ in the present study, i.e. the AUC of triazolam was more than doubled and the $t_{\frac{1}{2}, z}$ was nearly doubled by fluconazole $100 \mathrm{mg}$, when compared with the placebo phase [2].

Fluconazole has also been shown to interact with other substrates of CYP3A, e.g. cyclosporine and terfenadine [7-9]. The reports about these interactions are controversial, however, and the discrepancies may reflect the dose-dependent nature and large interindividual variation of the fluconazole interactions. In some case reports, fluconazole $100 \mathrm{mg}$ and $200 \mathrm{mg}$ changed the pharmacokinetics of cyclosporine, while in other reports no such change was noticed [7]. In one patient there was a sharp rise in cyclosporine trough concentration when the patient was taking fluconazole $300 \mathrm{mg}$, but no such increase occurred with fluconazole $100 \mathrm{mg}$ [7].

The antihistamine terfenadine has a clinically significant interaction with the antimycotics ketoconazole and itraconazole $[10,11]$. In the study of Honig et al. [8], patients were given fluconazole $200 \mathrm{mg} \mathrm{day}^{-1}$ simultaneously with terfenadine. Unmetabolized terfenadine was not detected in plasma in any subject, and cardiac depolarisation was not significantly changed. However, high dose fluconazole, $800 \mathrm{mg} \mathrm{day}^{-1}$, increased mean AUC of terfenadine by $52 \%$ [9]. Fluconazole $800 \mathrm{mg}$ $\mathrm{day}^{-1}$ was also associated with an increase in $\mathrm{Qt}_{\mathrm{c}}$. Our present and previous results indicate that triazolam and midazolam may be more sensitive than terfenadine to interact with fluconazole [12].

In vitro fluconazole is a competitive inhibitor of CYP2C whereas the inhibition of CYP3A mediated metabolism (of midazolam) did not appear to be competitive. Fluconazole is a considerably less potent inhibitor of CYP3A mediated metabolism than either ketoconazole or itraconazole in vitro, with a $K_{\mathrm{i}}$ greater than $80 \mu \mathrm{M}$ (ketoconazole $3 \mu \mathrm{M}$, itraconazole $6 \mu \mathrm{M}$ ) [13]. In vivo therapeutic plasma concentrations of fluconazole are about 100-fold higher than those of itraconazole. Furthermore, about $90 \%$ of fluconazole in plasma is present as free drug, whereas the free fraction of itraconazole is of the order of $1 \%[14,15]$. With daily doses of fluconazole $100 \mathrm{mg}$, the steady-state plasma concentration of fluconazole is about $5-10 \mathrm{mg} 1^{-1}$ $\left(15-35 \mu \mathrm{mol} 1^{-1}\right)$, i.e. less than the $K_{\mathrm{i}}$ of $80 \mu \mathrm{M}$. The 


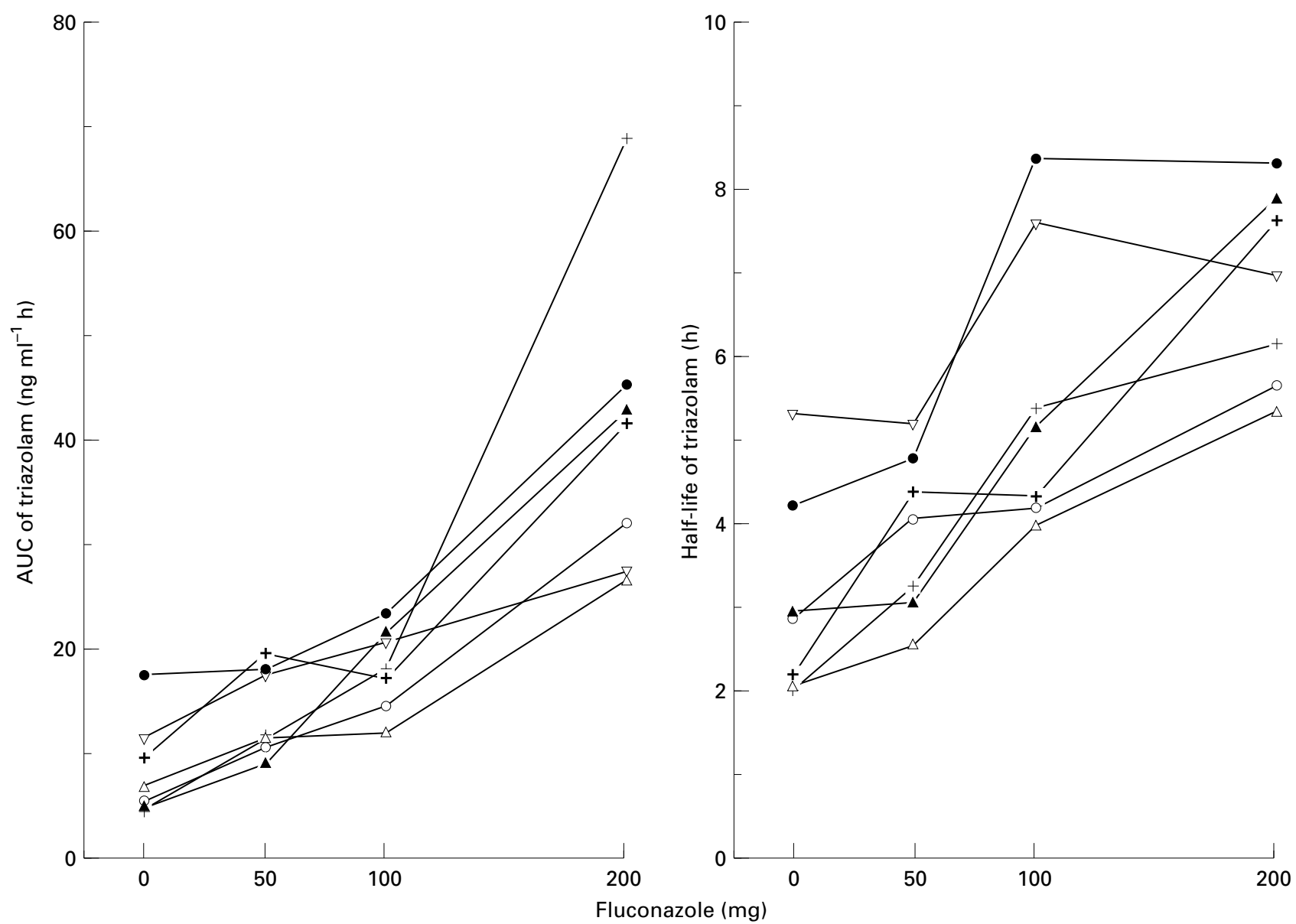

Figure 2 The individual AUC and $t_{\frac{1}{2}}$ values of triazolam during the control phase and three fluconazole phases (i.e. fluconazole 50, 100 and $200 \mathrm{mg}$ ) in eight subjects.

Table 1 The pharmacokinetic variables of triazolam $0.25 \mathrm{mg}$ (mean \pm s.e. mean or median and range) following pretreatment with different daily doses of fluconazole or placebo for 4 days in eight healthy volunteers. $95 \%$ confidence intervals for the ratio of the fluconazole and placebo phases are presented

\begin{tabular}{|c|c|c|c|c|}
\hline Variable & $\begin{array}{l}\text { Placebo } \\
\text { (Control) }\end{array}$ & $\begin{array}{l}\text { Fluconazole } \\
50 \mathrm{mg}\end{array}$ & $\begin{array}{l}\text { Fluconazole } \\
100 \mathrm{mg}\end{array}$ & $\begin{array}{l}\text { Fluconazole } \\
\quad 200 \mathrm{mg}\end{array}$ \\
\hline$C_{\max }\left(\mathrm{ng} \mathrm{ml}^{-1}\right)(95 \% \mathrm{CI})$ & $1.5 \pm 0.2$ & $\begin{array}{c}2.2 \pm 0.3^{\mathrm{a}, \mathrm{d}} \\
(108 \%, 207 \%)\end{array}$ & $\begin{array}{c}2.1 \pm 0.1^{\mathrm{a}, \mathrm{d}} \\
(94 \%, 234 \%)\end{array}$ & $\begin{array}{l}3.5 \pm 0.4^{\mathrm{b}} \\
(133 \%, 444 \%)\end{array}$ \\
\hline$t_{\max }(\mathrm{h})$ & $1.3(0.5,3.0)^{*}$ & $1.5(0.5,4.0)^{*}$ & $2.5(1.0,4.0)^{*}$ & $2.0(0.5,3.0)^{*}$ \\
\hline $\begin{array}{l}\operatorname{AUC}(0,18 \mathrm{~h})\left(\mathrm{ng} \mathrm{ml}^{-1} \mathrm{~h}\right) \\
(95 \% \mathrm{CI})\end{array}$ & $9.2 \pm 1.6$ & $\begin{array}{l}14.6 \pm 1.6^{\mathrm{b}, \mathrm{d}} \\
(125 \%, 235 \%)\end{array}$ & $\begin{array}{l}18.3 \pm 1.4^{\mathrm{c}, \mathrm{d}} \\
(138 \%, 347 \%)\end{array}$ & $\begin{array}{l}33.6 \pm 4.0^{\mathrm{c}} \\
(195 \%, 798 \%)\end{array}$ \\
\hline $\begin{array}{l}\mathrm{AUC}\left(\mathrm{ng} \mathrm{ml}^{-1} \mathrm{~h}\right) \\
(95 \% \mathrm{CI})\end{array}$ & $9.2 \pm 1.7$ & $\begin{array}{l}15.0 \pm 1.7^{\mathrm{b}, \mathrm{d}} \\
(130 \%, 234 \%)\end{array}$ & $\begin{array}{l}18.9 \pm 1.6^{\mathrm{c}, \mathrm{d}} \\
(142 \%, 357 \%)\end{array}$ & $\begin{array}{l}40.7 \pm 4.8^{c} \\
(238 \%, 949 \%)\end{array}$ \\
\hline $\begin{array}{l}t_{\frac{1}{2}, \mathrm{z}}(\mathrm{h}) \\
(95 \% \mathrm{CI})\end{array}$ & $3.1 \pm 0.4$ & $\begin{array}{c}4.0 \pm 0.3^{\mathrm{a}, \mathrm{d}} \\
(102 \%, 170 \%)\end{array}$ & $\begin{array}{c}5.5 \pm 0.6^{\mathrm{c}, \mathrm{d}} \\
(140 \%, 229 \%)\end{array}$ & $\begin{array}{l}7.0 \pm 0.4^{\mathrm{c}} \\
(167 \%, 323 \%)\end{array}$ \\
\hline
\end{tabular}

* Median (range). ${ }^{\text {a }}$ Significantly $(P<0.05)$ different from the placebo phase. ${ }^{\text {b }}$ Significantly $(P<0.01)$ different from the placebo phase. ${ }^{\mathrm{c}}$ Significantly $(P<0.001)$ different from the placebo phase. ${ }^{\mathrm{d}}$ Significantly $(P<0.05)$ different from the fluconazole $200 \mathrm{mg}$ phase.

concentration of fluconazole in the gut wall and liver can be considerably higher than in plasma, especially during absorption; this increases the probability of a significant interaction between fluconazole and triazolam. Liver:plasma partition coefficients for fluconazole in rat are concentration dependent ranging from 30 to 2 [16]. At fluconazole concentrations of $15-35 \mu \mathrm{mol}$ $1^{-1}$ the partition coefficient is approximately $2-4$.
In conclusion, although fluconazole has a smaller risk than either itraconazole or ketoconazole to interact with triazolam, daily fluconazole doses of $50 \mathrm{mg}$ or more may cause a significant interaction. There are interindividual differences between subjects in the extent of the interaction, but this increases along with the dose and plasma concentrations of fluconazole. If used simultaneously with fluconazole $100 \mathrm{mg}$ or $200 \mathrm{mg} \mathrm{day}^{-1}$, the 

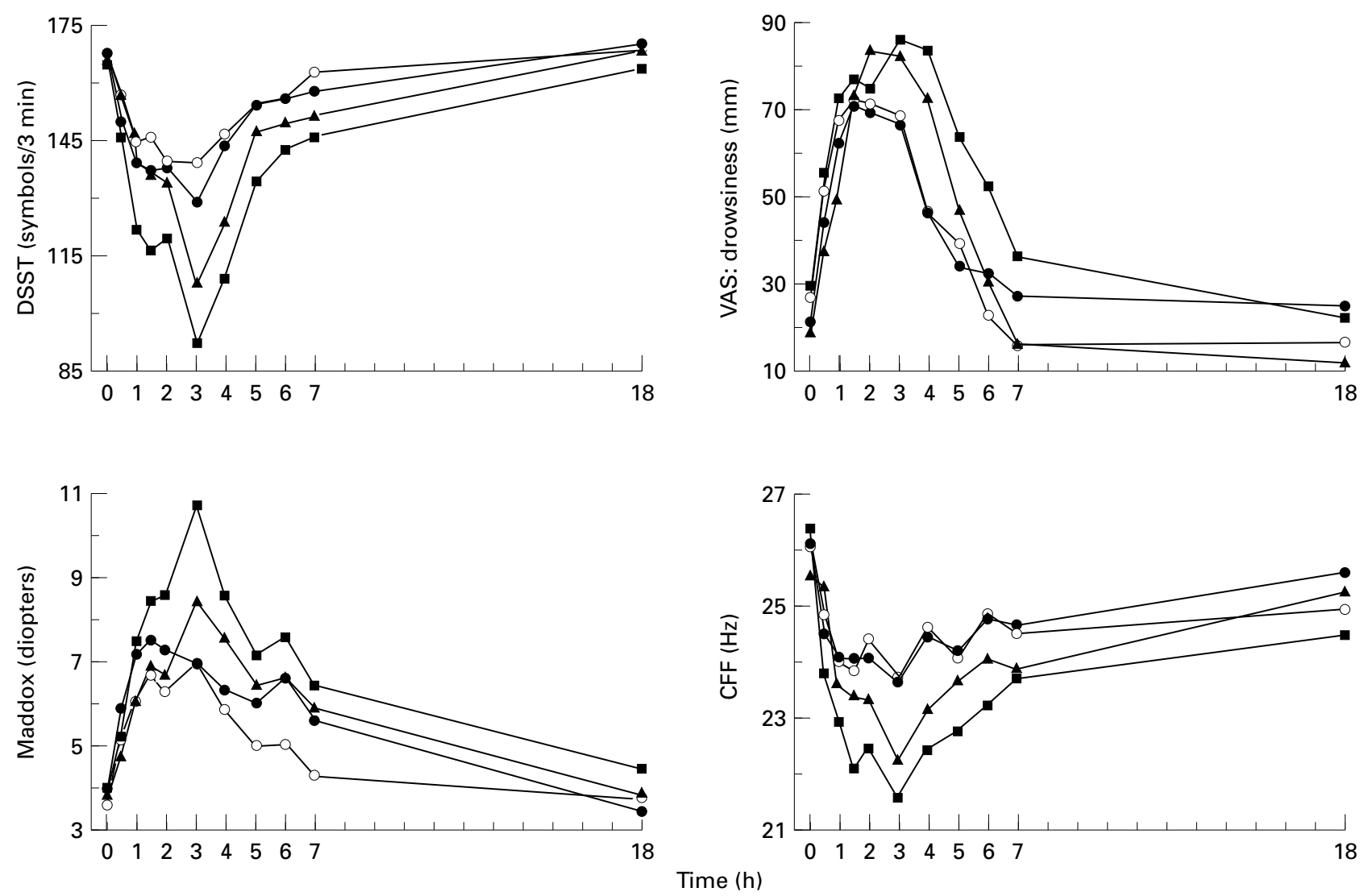

Figure 3 Results of the digit symbol substitution test (DSST), subjective drowsiness (VAS), the critical flicker fusion test $(\mathrm{CFF})$ and the Maddox wing test after an oral $0.25 \mathrm{mg}$ dose of triazolam following pretreatment with fluconazole $50 \mathrm{mg}(\bullet)$, $100 \mathrm{mg}(\mathbf{\Delta}), 200 \mathrm{mg}(\boldsymbol{\square})$ or placebo $(\bigcirc)$. Mean values of eight subjects.

dose of triazolam, for example, should be reduced by $50-75 \%$. The concomitant use of triazolam and high doses of fluconazole cannot be recommended.

We thank Mr Jouko Laitila, Mrs Eija Mäkinen-Pulli and Mrs Lisbet Partanen for determining plasma triazolam and fluconazole concentrations.

\section{References}

1 Kronbach T, Mathys D, Umeno M, Gonzales FJ, Meyer UA. Oxidation of midazolam and triazolam by human liver cytochrome P450IIIA4. Mol Pharmacol 1989; 36: 89-96.

2 Varhe A, Olkkola KT, Neuvonen PJ. Fluconazole, but not terbinafine, interacts with triazolam. Br J Clin Pharmacol 1996; 41: 319-323.

3 Varhe A, Olkkola KT, Neuvonen PJ. Oral triazolam is potentially hazardous to patients receiving systemic antimycotics ketoconazole or itraconazole. Clin Pharmacol Ther 1994; 56: 601-607.

4 De Kroon IFI, Langendijk PNJ, De Goede PNFC. Simultaneous determination of midazolam and its three hydroxy metabolites in human plasma by electron-capture gas chromatography without derivatization. J Chromatogr 1989; 491: 107-116.

5 Gaillard Y, Gay-Montchamp J-P, Ollagnier M. Simultaneous screening and quantitation of alpidem, zolpidem, buspirone and benzodiazepines by dual-channel gas chromatography using electron-capture and nitrogen- phosphorus detection after solid-phase extraction. J Chromatogr 1993; 622: 197-208.

6 Harris SC, Wallace JE, Foulds G, Rinaldi MG. Assay of fluconazole by Megabore Capillary Gas-Liquid Chromatography with Nitrogen-Selective Detection. Antimicrobial Agents Chemother 1989; 33: 714-716.

7 Lopez-Gill JA. Fluconazole-cyclosporine interaction: a dose dependent effect? Ann Pharmacother 1993; 27: 427-430.

8 Honig PK, Wortham DC, Zamani K, Mullin JL, Conner DP, Cantilena LR. The effect of fluconazole on the steadystate pharmacokinetics and electrocardiographic pharmacodynamics of terfenadine in humans. Clin Pharmacol Ther 1993; 53: 630-636.

9 Cantilena LR, Sorrels S, Wiley T, Wortham D. Fluconazole alters terfenadine pharmacokinetics and electrocardiographic pharmacodynamics. Clin Pharmacol Ther 1995; 57: 185. [Abstract]

10 Honig PK, Wortham DC, Zamani K, Conner DP, Mullin JL, Cantilena LR. Terfenadine-ketoconazole interaction: pharmacokinetic and electrocardiographic consequences. JAMA 1993; 269: 1513-1518.

11 Pohjola-Sintonen S, Viitasalo M, Toivonen L, Neuvonen PJ. Itraconazole prevents terfenadine metabolism and increases risk of torsades de pointes ventricular tachycardia. Eur J Clin Pharmacol 1993; 45: 191-193.

12 Olkkola KT, Ahonen J, Neuvonen PJ. The effect of the systemic antimycotics, itraconazole and fluconazole, on the pharmacokinetics and pharmacodynamics of intravenous and oral midazolam. Anesth Analg 1996; 82: 511-516.

13 Hargreaves JA, Jezequel S, Houston JB. Effect of azole antifungals on human microsomal metabolism of diclofenac 
470 A. Varhe et al.

and midazolam. Br J Clin Pharmacol 1994; 38: $175 \mathrm{P}$. [Abstract]

14 Grant SM, Clissold SP. Fluconazole: a review of its pharmacodynamic and pharmacokinetic properties, and therapeutic potential in superficial and systemic mycoses. Drugs 1990; 39: 877-916.

15 Arredondo G, Calvo R, Marcos F, Martínez-Jordá R, Suarez E. Protein binding of itraconazole and fluconazole in patients with cancer. Int J Clin Pharmacol Ther 1995; 33: $449-452$.
16 Ervine CM, Houston JB. Disposition of azole antifungal agents. III. Binding of fluconazole and other azoles in rat liver. Pharm Res 1994; 11: 961-965.

(Received 12 February 1995, accepted 12 June 1996) 